\title{
The Case Study of a Deep Pit Excavation above Multiple Metro Tunnels and Influential Factors Analysis on Tunnel Upheaval Behaviors
}

\author{
Gao Wei, Li Hai Bin, Wei Xuan Wan, and Zhang Ai Jun
}

\begin{abstract}
A municipal expressway in Shenzhen Qianhai cooperation zone, with the total length of 3 kilometers, would be constructed above multiple existing metro tunnels. The distance between the excavated pit bottom and tunnel roof ranges from $0.43 \mathrm{~m}$ to $4.86 \mathrm{~m}$. Widely distributed marine mud and unplanned reclamation result in very complex geological conditions in the area. In order to control the possible upheaval movements, countermeasures had to be considered and taken seriously. A 3-D numerical analysis was applied for tunnels upheaval deformation prediction. Discussions were made on the influences from the unloading ratio, the unloading rate and the structure type of tunnels. Possible correlations and trends based on monitoring data were derived for tunnels upheaval movement assessment. Observations can be referred for future similar projects.
\end{abstract}

Index Terms-Metro tunnels, marine mud, deep excavation, upheaval deformation.

\section{INTRODUCTION}

With the urbanization process of cities, more and more underground spaces were exploited to satisfy the demands of modern city development. Consequently, deeper foundation pits, underground municipal express ways of transportation systems were planned and excavated. New construction measures were discussed and applied in projects [1]-[3].These projects, especially crossing above or adjacent to the existing metro tunnels result in new challenges and much more complex problems to engineers.

The original stress state around tunnels changed definitely due to excavations. As a result, stress redistribution took place in the soil body during the pit excavation and deformation of the tunnel structures may be inevitable. Influences from these excavations were studied by researchers [4]-[6].

\section{PROJECT BACKGROUND}

The project was located in Qianhai Shenzhen-Hong Kong Modern Service Industry Cooperation Zone. As a very important municipal underground expressway, the planned total length is $3.15 \mathrm{~km}$ with $60 \mathrm{~m}$ in width. Approximate 200

Manuscript received July 26, 2016; revised October 23, 2016.

Gao Wei and Li Hai Bin are with Shenzhen Integrated Geotechnical Investigation \&Surveying Co., Ltd, Shenzhen, China (e-mail: gaow@szkan.com.cn,95426234@qq.com).

Wei Xuan Wan is with Shenzhen Municipal Design and Research Institute Co., Ltd, Shenzhen, China (e-mail: 377244262@qq.com).

Zhang Ai Jun is with School of Civil Engineering, Guangzhou University, Guangzhou, China (e-mail: 42175316@qq.com). meters expressway will be constructed above 3 metro lines (Fig. 1). The average excavation depth above the current metro tunnels is about $8.0 \mathrm{~m}$ and the maximum depth reached $11.5 \mathrm{~m}$ (Table I, Fig. 2).

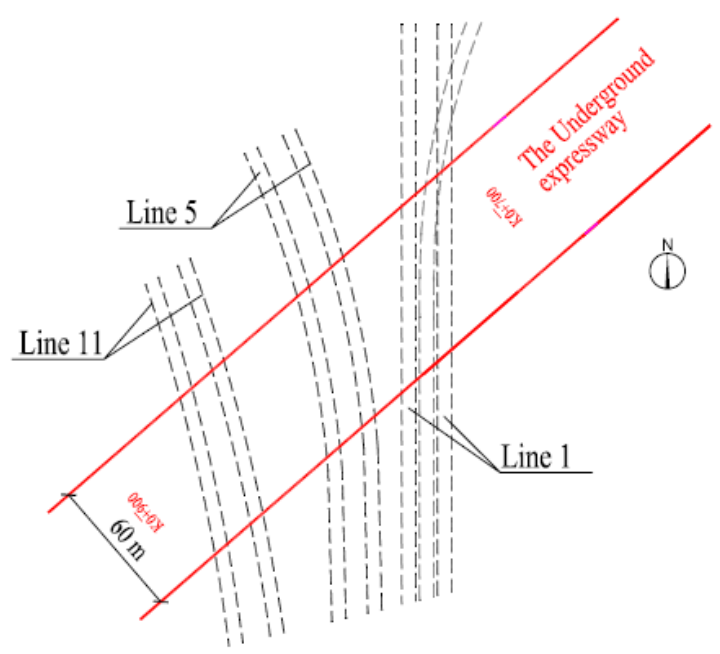

Fig. 1. The plan view of the underground expressway above 3 metro tunnels ( line 1,5,11).

TABLE I: THE SPATIAL RELATIONS BETWEEN TUNNELS AND EXPRESSWAY EXCAVATION PITS

\begin{tabular}{|c|c|c|c|}
\hline & $\begin{array}{c}\text { Excavation } \\
\text { depth above } \\
\text { tunnels }(\mathrm{m})\end{array}$ & $\begin{array}{c}\text { Minimum distance } \\
\text { between tunnels and } \\
\text { pit bottom }(\mathrm{m})\end{array}$ & $\begin{array}{c}\text { Tunnel length } \\
\text { under the } \\
\text { expressway }(\mathrm{m})\end{array}$ \\
\hline Line 1 & $3.0 \sim 4.75$ & 0.43 & 83 \\
\hline Line 5 & $4.0 \sim 5.55$ & 4.86 & 79 \\
\hline Line 11 & $7.0 \sim 11.5$ & 3.25 & 73 \\
\hline
\end{tabular}

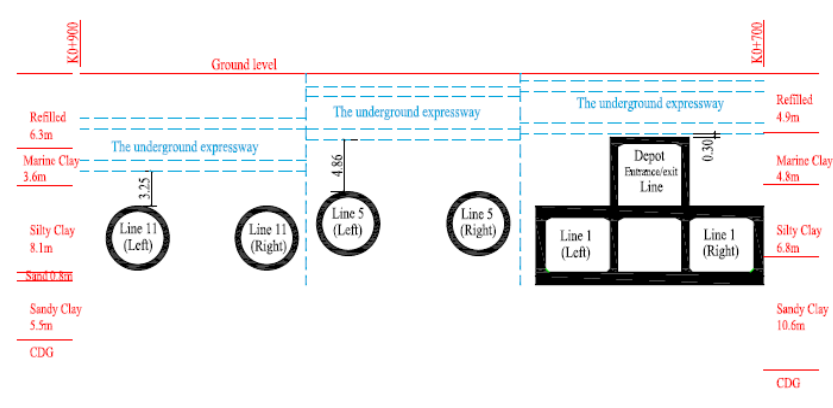

Fig. 2. The cross-section description between tunnels and the above excavation pits.

The area of project location was reclaimed for years, however, the reclamation processes were not well planned and performed. Thus, the geological conditions were very complicated and the strata distribution was disordered. Generally, the top refilled soil, marine soft clay, silty clay (alluvium), coarse sand and underlying CDG formed the 
main geological layers. The details of soil layers are listed in Table II.

The stable ground water table is around $1.0 \mathrm{~m}$ just below the ground surface, which is closely affected by the outer sea.

TABLE II: THE SOIL PROPERTIES

\begin{tabular}{|c|c|c|c|}
\hline Description & $\begin{array}{c}\text { Cohesion } \\
(\mathrm{kPa})\end{array}$ & $\begin{array}{c}\text { Friction } \\
\text { Angle }\end{array}$ & $\begin{array}{c}\text { Deformation modulus } \\
(\mathrm{MPa})\end{array}$ \\
\hline Refilled & - & 40 & - \\
\hline Marine clay & 8 & 2 & 4 \\
\hline Silty clay & 20 & 18 & 12 \\
\hline Coarse sand & - & 30 & 15 \\
\hline Sandy Clay & 25 & 18 & 16 \\
\hline CDG & 25 & 30 & 35 \\
\hline
\end{tabular}

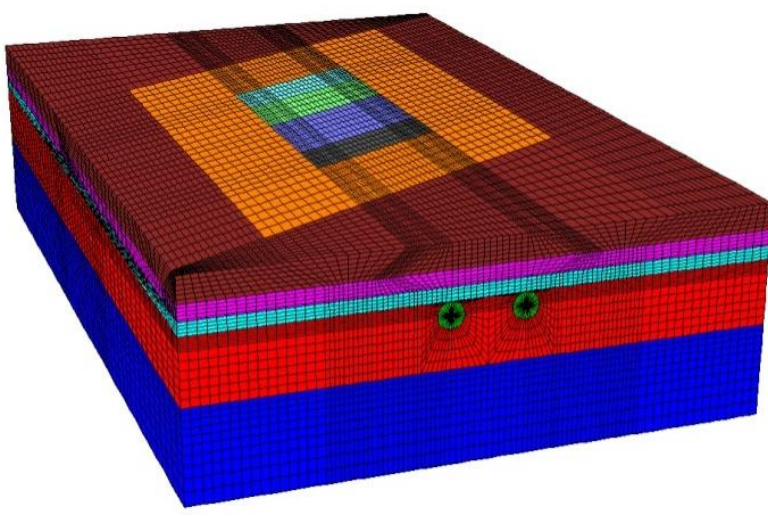

Fig. 3. Meshed model in FLAC.

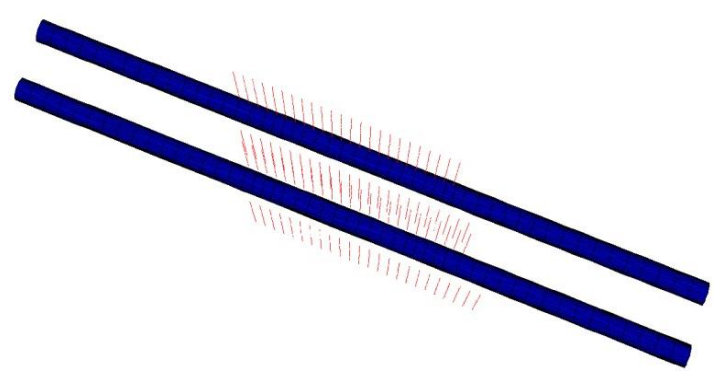

Fig. 4. The models of metro tunnels and anti-uplift piles.

\section{NUMERICAL ANALYSIS AND COUNTERMEASURES DESIGN}

In addition to the excavation safety consideration of the expressway pits, more significant issue to engineers is how to control the consequent upheaval movements due to large upper soil body discharging. However, few similar projects and experiences can be referred in such conditions in Shenzhen.

Due to few experiences and big challenge confronted to engineers, three-dimensional numerical analysis is still recommended for trend prediction of tunnel deformation before construction. FLAC3D was usually used to predict the deformation trend induced by the deep excavation [7]. It was mainly regarded as a necessary approach before construction to understand the potential risks for alert and risk management purpose. Moreover, necessary optimization of construction procedures and countermeasure methods could be suggested in this way.

The soil and the rock are described by modified cam-clay model and Mohr-Coulomb model, respectively. The supporting wall and tunnel lining are assumed to be linear elastic. The large-dimensional manual-digging pile is simulated by solid element. Fig. 3 and Fig. 4 show the meshed 3-D model and the underlying metro tunnel models, respectively.

The deformation prediction results can be referred in Table III. According to possible countermeasures and procedures simulated for tunnels deformation controlling in numerical analysis, the principles for pit excavation and tunnels protection design were discussed seriously and suggested as follows:

1) Measures, such as soil reinforcement above tunnels, groundwater level maintaining are necessary and must be carried out before pit excavation.

2) Soil discharging of pit excavation in a time and space limitation order plays a significant role for upheaval deformation.

3) Constructing anti-uplift piles before pit excavation and building anti-upheaval structural system as soon as possible while the pit bottom level has been reached.

\section{DEFORMATION MONITORING AND ANALYSIS}

\section{A. Upheaval Movements Monitoring during Excavation}

During the whole construction of the municipal expressway, especially the pit excavation, the horizontal and vertical displacements of the metro tunnels were monitored in a spatial interval of 10 meters along the tunnels. Factual data curves were obtained and listed in the following figures (Fig. 5, Fig. 6, Fig. 7).

The days of monitoring for data collection last over a year in order to cover the entire construction period. Generally, six main phrases were differentiated and experienced: (1) large area soil discharging for ground leveling;(2) soil backfilling (only if deformations go fast);(3) pit excavation;(4) anti-upheaval structures construction;(5) bottom plate construction;(6) main structure construction.

TABLE III: THE COMPARISON BETWEEN NUMERAL ANALYSIS RESULTS AND FACTUAL MONITORING DATA

\begin{tabular}{|c|c|c|c|c|}
\hline \multirow[t]{2}{*}{$\begin{array}{l}\text { Metro } \\
\text { lines }\end{array}$} & \multicolumn{2}{|c|}{$\begin{array}{l}\text { The predicted maximum } \\
\text { upheaval deformation values } \\
(\mathrm{mm})\end{array}$} & \multicolumn{2}{|c|}{$\begin{array}{l}\text { The maximum monitored } \\
\text { upheaval deformation values } \\
\text { ( } \mathrm{mm})\end{array}$} \\
\hline & Left tunnel & Right tunnel & Left tunnel & Right tunnel \\
\hline Line 1 & 7.5 & 6.0 & 8.9 & 6.1 \\
\hline Line 5 & 17.5 & 14.5 & 19.1 & 16.4 \\
\hline Line 11 & 20.0 & 20.5 & 24.0 & 23.0 \\
\hline
\end{tabular}

Observations can be made:

\section{1) Different deforming tendency may be influenced by types of metro tunnels}

Different shape of metro tunnels can be found. The shape of line 5 and 11 is TBM-shaped circle, and line 1 shape is 
frame-structured combination. Larger upheaval deformation (over $16 \mathrm{~mm}$ ) was more easily induced when the tunnel was TBM-shaped (Line 5, line 11). The frame-structured tunnel (line1) tends to be more stable with a larger cubic body and the maximum deformation is observed less than $10 \mathrm{~mm}$. The type and stiffness of tunnels may be one of major factors to control the final deformation

In addition, line 1 was constructed in an opening excavation and backfilling manner, and the underlying soil strata had already experienced a rebound-recompress process. Therefore, most rebounding behavior of underlying soil strata has taken place, which left small deformation potential during the re-excavation process.

\section{2) Different behavior of tunnel deformation may be} decided by soil discharging manners

Different from a steady developed upheaval curve in line 1 , very obvious sharp upheaving and falling movements of tunnels can be observed in line 5 (days from 0 to 160) and line 11 (days from 0 to 90) respectively.

Actually, it was caused by a quick soil digging for ground leveling purpose above line 5 and line 11 . The soil body in a large area above (2.5 meters thick) was dug out in several days by contractors without any authorized plan. A very large deformation value was monitored subsequently $(15 \mathrm{~mm}$ in line 11 and 5). Quick backfilling has to be carried out immediately to stop this abrupt upheaval development trend. Soil discharging of pit excavation above line 1 was controlled in a time and space limitation order, and the deformation developed steady accordingly. It proved that any quick soil discharging without a gradual digging step easily result in an unexpected upheaval movement.

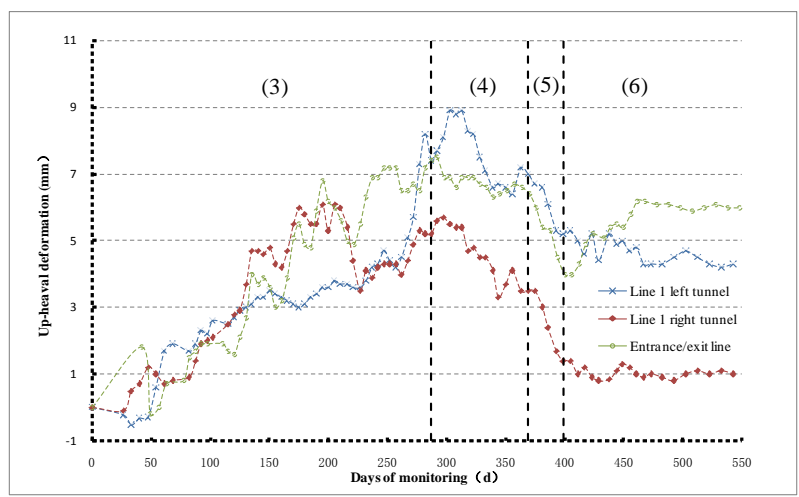

Fig. 5. The monitored upheaval movement of metro line 1.

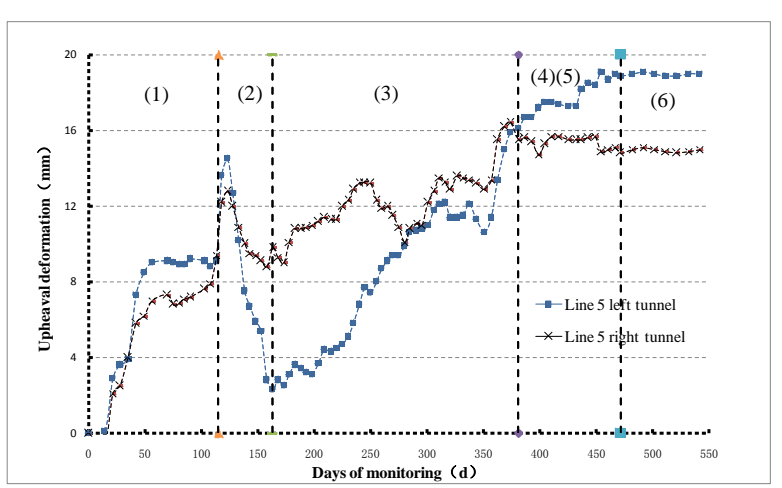

Fig. 6. The monitored upheaval movement of metro line 5 .

\section{B. Influential Factors Discussion}

In our study, all discussions are based on the factually collected monitoring data. The factors to influence tunnels upheaval behavior may include geological conditions, excavation manners, tunnel types and protection measures etc.

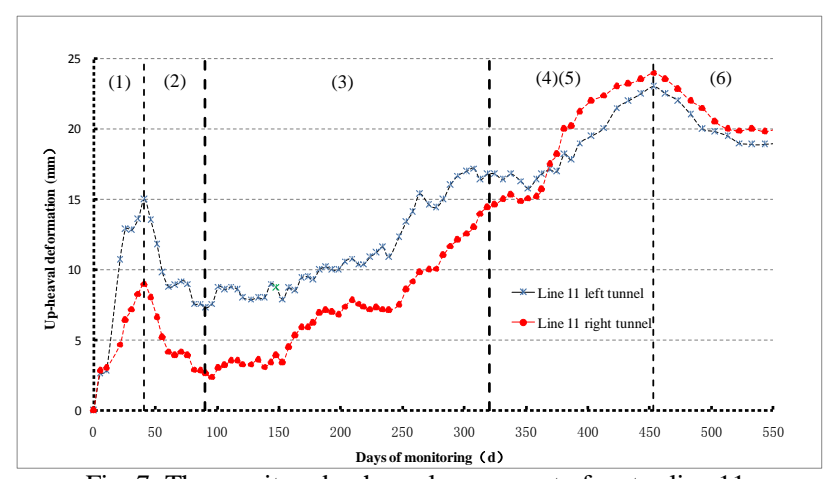

Fig. 7. The monitored upheaval movement of metro line 11.

Difference in strata properties underlying tunnels and other geological conditions, such as underground water definitely existed in this project. But in our assumption, this kind of differences were relatively small and not analyzed. In this way, the possible influential factors from unloading ratio, unloading rate and the tunnel structure type were mainly discussed.

\section{3) The unloading ratio}

The parameter is to analysis and find out the unloading effect from the above soil discharging. It reflects how much the soil has been dug out and can be defined as:

Unloading Ratio (UR) = Excavated depth/original soil thick above the tunnel

This parameter was mentioned in some of papers [1] and cases of excavations above tunnel were simply described. It is a dimensionless parameter.

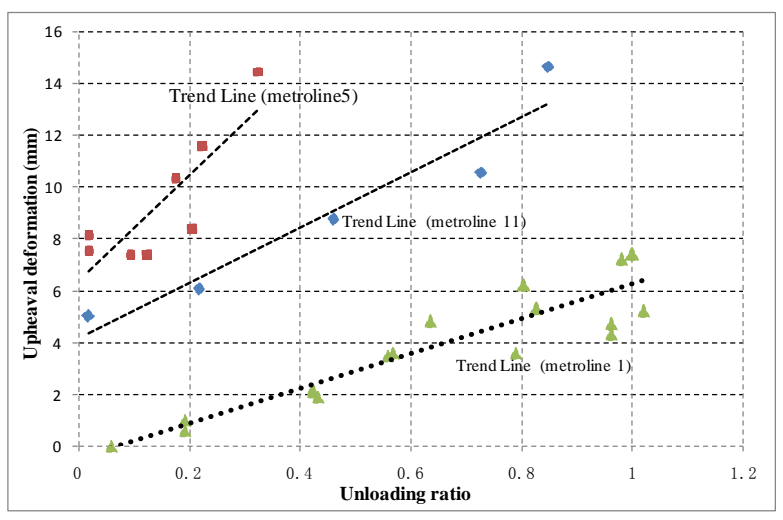

Fig. 8. The trend lines based on unloading ratio.

Some possible linear relationships were obtained, which indicated the upheaval deformation developed increasingly while above more soil was dug out. According to Fig.8, if a same unloading ratio is given, the upheaval deformation of three tunnels should be: line $5>$ line $11>$ line 1 . Actually, the monitored maximum deformation finally verified the relations because the ratio of maximum upheaval deformed values to the actual excavated depth is $0.36 \%$ (line 5), $0.26 \%$ (line 11), $0.23 \%$ (line 1 ).

Attempt has also been made combining with cases in Shanghai [7], but no clear relations between upheaval deformation and unloading ratio can be derived. Factors like geological formations, excavation manners, tunnel types and protection measures may be different in these projects but not be mentioned in the paper. 
Different start points of three regression lines can be observed. It does not make sense if we do not remember the quick soil digging in a large area above line 5 and line 11 took place. The jumped initial values based on less collected data during this period indicate a high sensitivity in case of quick unloading above tunnels.

\section{4) The unloading rate}

The unloading rate is a parameter to reflect how fast the above soil has been excavated. Unexpected abrupt upheaval deformation development was monitored soon after a quick unplanned soil digging. It is necessary to study whether the above unloading in different digging rate will be another significant factor to control the tunnels upheaval movement.

Data from these three metro lines were put together, and exponential correlations may be regressed based on the existing data according the construction logs. The upheaval movement rate of tunnels is obviously enlarged if the above soil is dug out in shorter time. According to Fig. 9, the trend line seems to be more dependent on data from metro line 5 and line 11, and data of unloading rate above line 1 look more concentrated within a small range. The unplanned soil digging and pit excavation made the unloading rate vary from 0 to $2.5 \mathrm{~m} / \mathrm{month}$, which appeared to cause the tunnels upheaval movement rate to change consequently all the time. But to line 1 , a steady unloading rate $(0.5-0.6 \mathrm{~m} / \mathrm{month})$ is corresponding to a relatively steady upheaval movement of tunnels $(0.5-1.2 \mathrm{~mm} / \mathrm{month}$, average value: $0.8 \mathrm{~mm} / \mathrm{month})$. These data points of line 1 are also near the regressed trend line.

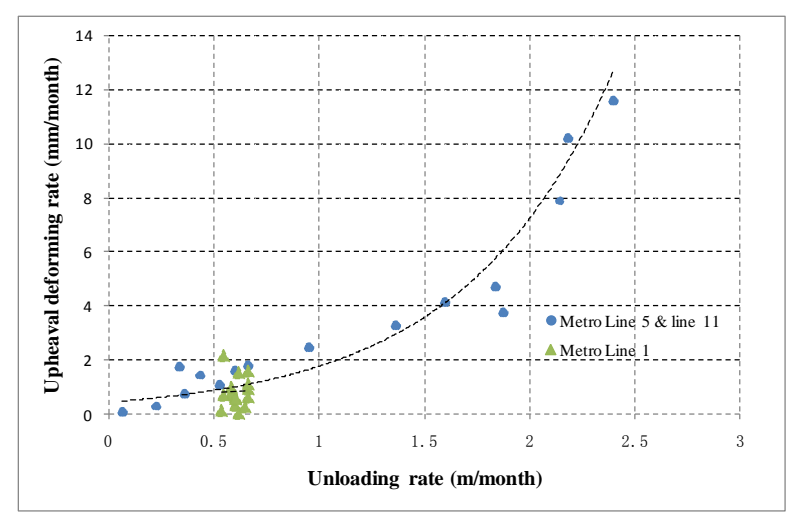

Fig. 9. The trend line based on unloading rate.

\section{5) The tunnel structure type}

The tunnel structure type is a key factor to be considered in the analysis. Although it is not easy to evaluate accurately only based on data from this project, qualitative discussions about this influential factor are made as follows:

- Numeral analysis results and factual monitoring data have confirmed the effects from this structural difference (Table III). Larger upheaval deformation was more easily induced in case of TBM-shaped tunnel. In other words, comparing to the framestructured tunnel, TBM-shaped tunnel is more sensitive to the above soil discharging.

- It still makes sense that larger frame-structured tunnel is hard to move upward. In the analysis of either unloading ratio or unloading rate, metro line 1 tends to keep the upheaval deformation values and rates in a relatively low level.

\section{OBESERVATIONS AND SUMMARY}

The paper focuses on a case study of the upheaval movement of tunnels while deep pit excavations occurred. Even though similar protection measures have been taken, the upheaval trends of three metro lines appear different.

Discussions were made on the influences from the unloading ratio, the unloading rate and the structure type of tunnels based on the factual monitoring data. Some possible linear relationships indicated the upheaval process developed increasingly while more soil above tunnels was dug out in this project.

The soil unloading rate is another significant factor to influence the tunnels upheaval movement. The upheaval movement rate of tunnels is obviously increased if the above soil unloading rate is much quicker.

It is concluded that upheaval behavior of tunnels is still a very complex problem. Major factors, such as geological conditions, the unloading manners and tunnels types should be studied carefully so that the know-how can be accumulated and summarized gradually.

\section{ACKNOWLEDGMENT}

The authors wish to thank WEI Xuan Wan for his provision of monitoring data which are the important analytical basis for this paper.

\section{REFERENCES}

[1] S. L. Wen, "Study on construction technology and protection measures of the excavation above operating metro tunnel," Chinese Journal of Underground Space and Engineering, vol. 7, pp.14651469, Oct 2011.

[2] M. M. Liu, "Foundation excavation technology of Renmin road tunnel crossing above metro tunnel," Construction Technology, vol. 41 , no. 1 , pp. $75-77,2012$.

[3] S. L. Wen, "Construction technology of deep open excavation above running metro tunnels," Chinese Journal of Geotechnical Engineering, vol. 32, pp. 451-454, Aug. 2010.

[4] H. S. Jiang and X. Y. Hou, "The influence of deep excavation on adjacent metro tunneling in soft ground," Industrial Construction, pp. 53-56. 2002

[5] L. C. Kuang, Z. M. Li, and Z. Z. Yin, "Analysis of field measurement data on responses of metro tunnel due to substructure construction," Journal of Tsinghua University (Science and Technology), vol. 40 pp. 79-82, 2000.

[6] Z. Gang, Q. C. Liu, D. Xu et al., "Field measurement and analysis of effect of excavation on existing tunnel boxes of underlying metro tunnel in operating," Rock and Soil Mechanics, vol. 33, no. 4, pp. 1109-1116, 2012.

[7] J. F. Zhang, J. H. Wang, and J. J. Chen et al., "3-D FEM backanalysis of an oversize and deep excavation," Journal of Shanghai Jiaotong University, vol. 46, no. 1, pp. 42-46, 52. 2012.

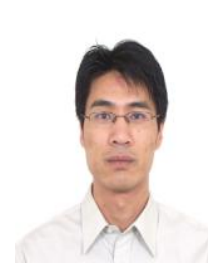

Gao Wei was born in Shandong province, China and the birth date is October 1974. He received his $\mathrm{PhD}$ degree in civil engineering from the University of Hong Kong in 2008. He also holds a MS degree in engineering mechanics from China University of Mining \& Technology, Beijing.

After his graduation, he focuses on the geotechnical engineering, such as site investigation and especially the design works for deep foundation pit excavation, ground improvement as well as high slope stability treatment. He is now working as the brief engineer in Shenzhen Integrated Geotechnical Investigation \& Surveying Co., Ltd, China. He participated many significant infrastructure projects construction as a known expert in Shenzhen.

Dr. Gao is the member of Shenzhen Civil Engineering \& Construction Institution, Shenzhen society of geotechnical investigation and design and HKIE. 